\section{Waiting rooms and the unconscious}

\author{
John Launer
}

If you ask patients what they dislike about seeing doctors, there is a fair chance they will mention having to sit in waiting rooms for ages. Doctors tend to get defensive when they hear this and are likely to offer reasons why it happens. These usually include the following. "There are never enough doctors, so we are always working against the clock.' 'Consultations are unpredictable and may go on longer than anyone expected, delaying others.' 'Doctors may be called away from a clinic or surgery to deal with emergencies, leaving remaining colleagues to fit in other patients'. 'Some patients will always fail to turn up for their appointments, and it is better to have others ready than to have doctors twiddling their thumbs.' And so on and so forth.

These explanations are not very convincing, and it is easy to find counterarguments. Consultation lengths and emergencies do vary, but they have a statistical pattern that you can monitor so you can adjust your booking system accordingly; it's just that most institutions don't bother to do so. (Does yours?) Some doctors regularly finish an hour or two late, yet their patients are still stacked up for appointments every session without the remotest chance they will ever be seen on time. When gaps do occur in sessions, doctors are usually happy to catch up on their phone calls and emails, review a patient's notes, or do some teaching; to suggest we should never wait for anyone else because our own time is more important is presumptuous and even insulting.

Essentially, all the reasons we offer for long waiting times fall under the general category of rationalisations: arguments that fail to convince anyone, but serve as good excuses for not changing anything we don't particularly want to. However, they make better sense in the light of several different theories from fields outside medicine, including the social sciences and psychology. These may not

Correspondence to Dr John Launer, London Deanery, London Department of Postgraduate Medical Education, Stewart House, London WC1B 5DN, UK;

jlauner@londondeanery.ac.uk be as familiar, or as comfortable, as the yarns we spin for ourselves, but they provide better ways of understanding what happens in practice, without the special pleading of professionals who have vested interests in the 'status quo'. Three kinds of theory are particularly helpful. They relate to power, ceremonies and the unconscious mind.

\section{POWER}

Although doctors tend to think of their relationships with patients in terms of care, almost everyone who has looked at these from the outside has seen them in terms of power. Many have drawn on the work of Michel Foucault, the French historian and philosopher. Foucault argued that power suffuses all human encounters, especially those involving professions and institutions. ${ }^{1}$ You only have to cast a critical eye on any interaction in the medical clinic to understand his basic premise. Consider, for example, the way that case notes are piled up tantalisingly on the reception desk for the doctors to come and fetch. It would be perfectly possible to give them to the patients themselves as they arrive, so they could spend time reading them and even (heaven forbid) write in them to correct errors or add personal details if they wish. In spite of this, most doctors find such an idea hard even to consider, because it challenges our innate assumptions about power relations in medical practice.

In fact, almost everything we do in the clinic sends clear signals to patients that we are the people who make and apply the rules, and they are the ones who are obliged to comply. We don't just express power in the way we behave towards patients. According to Foucault, it arises from the fundamental way that doctors see patients as bodies-what he termed 'the medical gaze'. Seen from his perspective, the way we organise our appointment systems is entirely consistent with everything else we do as doctors. It is one of a myriad of ways that we scrutinise and regulate people in order to take control of them. For much of the time, this may be partly concealed, but in waiting rooms it is there for everyone to see.

\section{CEREMONIES}

Even if we are able to regard the doctor-patient relationship in terms of power, it may still seem strange to think of our work in terms of ceremonies. Yet there are social scientists who commonly use this word to describe what goes on in medicine. They use it in a special sense, following the leading sociologist of institutions, Erving Goffman. When Goffman talked about ceremonies, he was referring to the way that institutions and their members implicitly impose a set of rules to instruct people how to behave.

One outstanding piece of medical research that applied this approach was Philip Strong's study of paediatric clinics entitled 'The Ceremonial Order of the Clinic'. ${ }^{2}$ Strong examined consultations with parents and asked questions, including: "Who has the right to criticise what is happening, what type of criticism is allowed, who has rights to the overall control of the interaction, and how far are topics and speaking rights pre-allocated?' Not surprisingly, his research showed that the doctors gave strong indications to parents about what it was legitimate to express in consultations about their children. The doctors were also the arbiters of what parents were allowed to consider as appropriate conduct in relation to their children, irrespective of whether this fell within the realm of medical expertise or not

Although Strong didn't draw an explicit analogy with the priesthood or with formal religious ceremonies, it isn't hard to see from his description how many of the traditional activities of the clergy have actually been re-assigned to doctors. If this seems improbable, you only have to think of the way that patients are lined up in many waiting rooms like a congregation at prayer, even facing the reception desk as if it was an altar. And when doctors emerge every few minutes from consulting rooms to retrieve a set of notes and then vanish again, it has a close resemblance to a Greek orthodox priest disappearing behind the icon screen, or the high priest of the Israelites entering the Tabernacle. Modern doctors, it seems, have done more than take on the moral function of priests. In the waiting room, they enact priestly forms of ritual as well.

\section{THE UNCONSCIOUS AT WORK}

While sociologists have looked at medical institutions using concepts such as power and ceremonies, organisational 
psychologists have brought rather different frameworks. Many who work in this field apply ideas taken from studying individuals, including an emphasis on the unconscious mind. One of the commonest principles they use for understanding clinical activity is that much behaviour that appears designed to meet the needs of patients may covertly be serving darker purposes. This can include protecting clinicians from unmanageable anxiety, or enacting a concealed wish to punish others. It is relatively easy to notice this in the way that some people behave at work: you have only to think of your most controlling or bossy colleagues in order to perceive. What is harder for many people is to accept that such psychological mechanisms are present in all of us, indeed universal in the caring professions, and may even guide how whole institutions function. Yet some psychologists argue this is indeed the case.
In a classic collection of essays about how the unconscious mind affects the workplace, Anton Obholzer and Vega Zagier Roberts look at both troubled organisations and healthy ones. ${ }^{3}$ They demonstrate that places such as waiting rooms are inevitably ones where we have licence to treat patients badly, and to make up credible excuses for doing so. Unlike most sociologists, however, they also offer remedies for this. They show how clinical teams can learn to acknowledge their own destructive tendencies and bring these under conscious control. They give examples of how professionals who can do this behave more compassionately towards patients, and indeed towards each other. Teams then feel free to start changing dysfunctional systems that seemed unchallengeable, or just part of the natural order of things. If Obholzer and Roberts are right-and I believe they are-each of us can take responsibility for changing some of the things that patients most dislike, or find inexcusable in doctors. An improvement in waiting times would be a good place to start.

Contributors John Launer.

Competing interests None.

Provenance and peer review Commissioned; internally peer reviewed.

Published Online First 3 May 2012

Postgrad Med J 2012;88:361-362.

doi:10.1136/postgradmedj-2012-131048

\section{REFERENCES}

1. Foucault M. The Birth of the Clinic: An Archaeology of Medical Perception. London: Vintage Books, 1994.

2. Strong PM. The Ceremonial Order of the Clinic: Parents, Doctors and Medical Bureaucracies. London: Routledge, 1979.

3. Obholzer 0, Zagier Roberts V. The Unconscious at Work: Individual and Organizational Stress in the Human Services. London: Routledge, 1994.

\section{Retraction}

Lloyd-Williams M, Dogra N. Attitudes of preclinical medical students towards caring for chronically ill and dying patients: does palliative care teaching make a difference? Postgrad Med J 2004;80:31-4. This article has been retracted.

Postgrad Med J 2012;88:362. doi:10.1136/pgmj.2003.009571ret 